\title{
Embalagens plásticas ameaçam a eficiência energética na produção de hortaliças orgânicas
}

\author{
Plastic packages threaten the energetic efficiency of vegetable \\ crop organic systems \\ Jacimar Luis de Souza ${ }^{1}$; Vicente Wagner D. Casali ${ }^{2}$; Ricardo Henrique S. Santos ${ }^{2}$; \\ Paulo Roberto Cecon ${ }^{3}$
}

\section{RESUMO}

A produção orgânica de hortaliças geralmente é direcionada a mercados onde o padrão de embalagem são as bandejas de poliestireno expandido e filmes plásticos de polietileno. Contudo, além de poluentes ambientais, os plásticos são energeticamente caros. Assim, objetivou-se avaliar os custos energéticos e a participação relativa das embalagens no sistema orgânico de produção de 10 olerícolas. Os dados de campo foram coletados na área experimental de agricultura orgânica do INCAPER, em Domingos Martins-ES, de 1991 a 2000. A mensuração energética consistiu na transformação dos materiais, insumos, produtos e serviços, em unidades de energia equivalentes. O sistema orgânico consumiu, em média, $1.906 .302 \mathrm{kcal} \mathrm{ha}^{-1}$ com embalagens, de um total de $4.571 .159 \mathrm{kcal} \mathrm{ha}^{-1}$. Em média, as embalagens corresponderam a 35,8\% do total do consumo de energia na produção orgânica. A participação das embalagens no consumo energético variou de $4,6 \%$ para a abóbora até $57,4 \%$ para o tomate. A eliminação dos gastos com embalagens poderia reduzir os custos, aumentando o balanço energético médio de 2,84 para 5,18.

Palavras-chave: Agricultura orgânica; poliestireno; polietileno; balanço energético.

\begin{abstract}
Vegetable crop organic production is frequently directed to markets where the package standards are the expanded polystyrene tray and polyethylene plastic films. Nevertheless, plastics are energetically expensive and are environmental pollutants. This study aimed to evaluate the energetic costs and the share of the package in the organic production system of 10 vegetable crops. Field data were collected at the organic agriculture experimental area of INCAPER, Domingos Martins - ES, from 1991 to 2000. The energetic quantification consisted of the transformation of tools, inputs, yield and services into equivalent energy units. The organic system required an average of 1,906,302 $\mathrm{kcal} \mathrm{ha}^{-1}$ as a package, out of a total cost of 4,571,159 $\mathrm{kcal} \mathrm{ha}^{-1}$. The package share of the energetic cost ranged from $4.6 \%$ in squash production to $57.4 \%$ in tomato production. The package was responsible for an average of $35.8 \%$ of the energetic cost of the production of 10 vegetable crops. The elimination of package costs would strongly reduce the energetic costs, increasing the mean energetic balance of 2.84 to 5.18 .
\end{abstract}

Key words: Organic agriculture; polystyrene; polyethylene; energetic balance.

\section{Introdução}

Além dos problemas sociais, ambientais e de saúde, a agricultura convencional é questionada por sua baixa eficiência no uso e transformação da energia. Nas últimas décadas, a chamada "modernização" da agricultura tem priorizado a alocação de quantidades cada vez maiores de energia nos sistemas produtivos, visando aumentar os rendimentos, causando redução na eficiência energética.

Os insumos industriais demandam grande quantidade de energia para sua fabricação. Como exemplos, o uso de fertilizantes à base de nitrogênio (14.930 kcal kg-1 - Felipe Júnior et al., 1984; citado por Ferraro Júnior, 1999), o uso de herbicidas (83.572 $\mathrm{kcal} \mathrm{L}^{-1}$ - Pimentel, 1980) e uso de óleo

1 INCAPER - Centro Serrano, BR-262, Km 94, 29.375-000 Venda Nova do Imigrante, ES, Brasil. E-mail: jacimarsouza@ yahoo.com.br. Autor para correspondência.

2 UFV - Departamento de Fitotecnia, Campus Universitário, 36.570-000 Viçosa - MG, Brasil.

3 UFV - Departamento de Informática, Campus Universitário, 36.570-000 Viçosa - MG, Brasil.

Fecha de Recepción: 05 Marzo, 2008

Fecha de Aceptación: 28 Enero, 2011 
diesel (8.484 $\mathrm{kcal} \mathrm{L}^{-1}$ - Ministério, 2005), resultam em grandes aportes de energia nos sistemas de produção convencional. Existe ainda o agravante de que grande parte desse aporte de energia seja originada, direta ou indiretamente, de fontes não renováveis, principalmente dos combustíveis fósseis (Pimentel et al., 1990; Gliessman, 2000).

O emprego de práticas que reduzam gastos de energia pode ser a alternativa para o aumento da eficiência dos sistemas produtivos, especialmente pelo emprego de rotações de cultura e manejo de espécies próprias para adubação verde, para cobertura do solo e fixação de carbono e nitrogênio (Li et al., 2002; Santos et al., 2000; Uri et al., 1998).

As agriculturas de base ecológica propõem a utilização de insumos de origem biológica ou pouco industrializados. Além desses insumos permitirem ou serem resultantes de processos de reutilização ou reciclagem, estes apresentam menor custo energético. Muitos estudos que comparam sistemas orgânicos com sistemas convencionais de produção, em várias partes do mundo, indicam maior aproveitamento da energia e maior taxa de conversão energética dos sistemas orgânicos de produção, tanto de hortaliças como de frutas e grãos (Mansvelt et al., 1998; Waldon et al., 1998; Reganold et al., 2001; Poudel et al., 2002).

A bibliografia científica, nacional e internacional, ainda é bastante limitada em trabalhos dedicados ao estudo do fluxo de energia em sistemas orgânicos, principalmente envolvendo espécies de hortaliças. Estudos sobre os custos energéticos dos diversos componentes dos sistemas de produção também são muito escassos.

$\mathrm{Na}$ agricultura orgânica, grande parcela das hortaliças orgânicas é direcionada a redes de supermercados ou pontos especiais de venda, visando atingir consumidores de elite. Para tanto, o padrão de embalagem mais usado são as bandejas de poliestireno expandido e filmes plásticos de polietileno, impulsionado pelas normativas do setor, que recomendam a proteção do produto para evitar contaminações nas fases de transporte e comercialização. Os produtos seguem normas rigorosas de produção e são apresentados em embalagens modernas, com ótimo apelo visual. Contudo, além de sérios poluentes ambientais, os plásticos são energeticamente caros. Segundo Sakurai (2004) e IPT (2005), o valor energético dos plásticos é equivalente ao do óleo combustível e, por esta razão, podem constituir-se em grande dispêndio energético.

A preocupação com a contaminação ambiental e com os custos energéticos dos plásticos são realidades estabelecidas no setor. Mesmo assim, a embalagem plástica tem sido a prática mais comum, devido à ausência de alternativas de embalagens ecológicas e devido ao baixo preço dos plásticos, fazendo com que estas se tornem as mais viáveis economicamente ao produtor orgânico até o momento. Em contrapartida, o ideal tecnológico da agricultura orgânica deve atender aos requisitos de sustentabilidade ambiental e energética, priorizando o uso de materiais e insumos de fontes renováveis de energia no processo produtivo.

Assim, o objetivo deste trabalho foi avaliar os custos energéticos dos diversos componentes do sistema de produção, destacando as participações relativas das embalagens no total de energia gasta na produção de 10 culturas em sistema orgânico de produção.

\section{Material e Métodos}

\section{Descrição geral do local e coleta de dados}

Este trabalho foi realizado na área experimental de agricultura orgânica do INCAPER, município de Domingos Martins-ES, a $950 \mathrm{~m}$ snm. As coordenadas geográficas do local são $20^{\circ} 22^{\prime} \mathrm{S}$ e $41^{\circ} 03^{\prime}$ W. Nesta região, a temperatura média das máximas nos meses mais quentes está entre 26,7 e $27,8^{\circ} \mathrm{C}$ e a média das mínimas nos meses mais frios entre 8,5 e $9,4{ }^{\circ} \mathrm{C}$.

Os dados foram coletados durante 10 anos no período de 1991 a 2000, contemplando o monitoramento de 12 plantios de abóbora (Cucurbita moschata) de 1991 a 2000; 14 plantios de alho (Allium sativum) de 1991 a 1999; 8 plantios de batata (Solanum tuberosum) de 1991 a 1997; 9 plantios de batata-baroa (Arracacia xanthorrhiza) de 1991 a 2000; 13 plantios de batata-doce (Ipomoea batatas) de 1991 a 2000; 17 plantios de cenoura (Daucus carota) de 1991 a 1999; 12 plantios de couve-flor (Brassica oleracea var. botrytis) de 1992 a 1999; 15 plantios de repolho (Brassica oleracea var. capitata) de 1991 a 1999; 6 plantios de taro (Colocasia esculenta) de 1992 a 1999; 9 plantios de tomate (Lycopersicon esculentum) de 1992 a 2000. 


\section{Caracterização do sistema orgânico de produção}

Os métodos de produção, além de seguirem os princípios da Agroecologia (Souza e Resende, 2003), foram aplicados conforme as determinações da legislação brasileira. Entre os métodos empregados, destacam-se: Compostagem orgânica; Adubação verde; Manejo de ervas espontâneas; Cobertura viva e morta; Rotação e sucessão de culturas, Controle alternativo de pragas e doenças. Os coeficientes técnicos médios (indicadores físicos) foram relatados por Souza (2005), acompanhando e monitorando o sistema orgânico de produção das 10 culturas nesta área experimental e apresentam-se na Tabela 1.

\section{Conversão do aporte e saída de energia}

A mensuração energética consistiu na transformação de todos os coeficientes técnicos (materiais, insumos, produtos e serviços) em unidades de energia ou unidades calóricas equivalentes, com base em Souza (2006). Por não encontrar padronização definida, a unidade de medida de energia foi a Quilocaloria (Kcal). O limite de contabilidade energética de cada cultura compreendeu as fases desde o preparo do solo até a entrega do produto no mercado, englobando os gastos com embalagem e frete.
Insumos orgânicos: Adotou-se o valor de $15 \mathrm{Kcal}$ $\mathrm{kg}^{-1}$ para resíduos vegetais e esterco de gado e o valor de $30 \mathrm{kcal} \mathrm{kg}^{-1}$ para outras fontes de esterco. Para o composto orgânico e o biofertilizante líquido, realizaram-se cálculos do processo de produção local. O composto totalizou $25.700 \mathrm{kcal}$ $\mathrm{kg}^{-1}$ a $50 \%$ de umidade final (forma utilizada nas adubações das culturas). $\mathrm{O}$ biofertilizante líquido somou $13 \mathrm{kcal} \mathrm{L}^{-1}$.

Sementes e mudas: Para sementes botânicas e propágulos vegetativos multiplicadas no próprio sistema orgânico, foram feitos cálculos dos gastos envolvidos nos processos, inserindo gastos com mão de obra na seleção, armazenamento e preparo das sementes e propágulos. Baseou-se nos valores de $2400 \mathrm{kcal} \mathrm{dia}^{-1}$ para a mão de obra, $0 \mathrm{kcal} \mathrm{kg}{ }^{-1}$ para restos culturais, sugerido por Ferraro Júnior (1999) e nos conteúdos calóricos dos produtos sugeridos por Franco (1999). Quanto às sementes adquiridas no mercado (Abóbora, Cenoura, Couve-flor e Repolho), optou-se pelo método que avalia os custos energéticos pelos custos financeiros da matriz energética brasileira, segundo Mello (1989). A obtenção do valor energético da moeda se deu pela razão entre o consumo de energia primária (kcal) e o PIB (Produto Interno Bruto, em Reais), no ano de 2004, ou seja, 1.008,4 kcal Real ${ }^{-1}$.

Tabela 1: Coeficientes técnicos e produtividades médias de 10 culturas olerícolas no sistema orgânico. INCAPER: Domingos Martins, ES, $2006^{1}$

\begin{tabular}{|c|c|c|c|c|c|c|c|c|c|}
\hline \multirow[b]{2}{*}{ Culturas } & \multicolumn{8}{|c|}{ Componentes } & \multirow[b]{2}{*}{$\begin{array}{c}\text { Produção } \\
\text { comercial } \\
\left(\mathrm{kgha}^{-1}\right)\end{array}$} \\
\hline & $\begin{array}{l}\text { Setnentes } \\
\text { ou mudas } \\
\text { (kg ou ud) }\end{array}$ & $\begin{array}{c}\text { Composto } \\
\text { (t) }\end{array}$ & $\begin{array}{c}\text { Caldas e } \\
\text { Insumes }^{2} \\
\text { (L) }\end{array}$ & $\begin{array}{c}\text { Servicos } \\
\text { Mecânicos } \\
(\mathrm{h} / \mathrm{t})\end{array}$ & $\begin{array}{l}\text { Mao Obra } \\
\quad(\mathrm{d} / \mathrm{h})\end{array}$ & $\begin{array}{c}\text { Irrigação } \\
\left(\mathrm{kwh} \mathrm{ha}^{-1}\right)\end{array}$ & $\begin{array}{c}\text { Embalagem } \\
\text { (ud) }\end{array}$ & $\begin{array}{c}\text { Frete } \\
\left(\mathrm{t} . \mathrm{km}^{-1}\right)\end{array}$ & \\
\hline Abóbora & 750 & 15 & 0 & 6,0 & 43 & 419 & 3.490 & 73,30 & 7.326 \\
\hline Alho & 800 & 30 & 6.400 & 6,0 & 306 & 637 & 12.200 & 61,02 & 6.102 \\
\hline Batata & 1.200 & 30 & 8.000 & 6,0 & 184 & 808 & 19.450 & 194,51 & 19.451 \\
\hline Batata-baroa & 27.800 & 20 & 0 & 6,0 & 180 & 590 & 30.710 & 153,55 & 15.355 \\
\hline Batata-doce & 33.000 & 30 & 0 & 6,0 & 144 & 367 & 21.630 & 216,30 & 21.630 \\
\hline Cenoura & 4 & 30 & 0 & 6,0 & 266 & 550 & 47.070 & 235,35 & 23.535 \\
\hline Couve-flor & 0,2 & 30 & 0 & 6,0 & 117 & 550 & 16.030 & 136,86 & 13.686 \\
\hline Repolho & 0,3 & 30 & 0 & 6,0 & 165 & 550 & 32.430 & 553,20 & 55.320 \\
\hline Taro & 2.000 & 20 & 0 & 6,0 & 163 & 590 & 23.800 & 238,05 & 23.805 \\
\hline Tomate & 0,25 & 30 & 40.000 & 6,0 & 400 & 772 & 69.090 & 345,45 & 34.545 \\
\hline
\end{tabular}

\footnotetext{
${ }^{1}$ Os valores, para cada espécie, são médias de vários cultivos no período de 1991 a 2000.
}

${ }^{2}$ Quantidade total referente a calda bordalesa e biofertilizante líquido. 
Adubos minerais e corretivos: Cal virgem (2.408 $\mathrm{kcal} \mathrm{kg}^{-1}$ - Mello, 1989); Sulfato de cobre (400 kcal $\mathrm{kg}^{-1}$, valor similar ao sulfato de potássio e magnésio, relatados por Ferraro Júnior, 1999).

Calda bordalesa: 18,6 kcal L-1 (cálculo baseado nos componentes e serviços).

Óleo diesel: $8.484 \mathrm{kcal} \mathrm{L}^{-1}$ (Ministério, 2005).

Energia elétrica: $860 \mathrm{kcal} \mathrm{kwh}^{-1}$, publicado no Boletim Energético Nacional de 2004, pelo Ministério das Minas e Energia (Ministério, 2005).

Serviços mecânicos: Aração (136.010 kcal ha $\left.{ }^{-1}\right)$, Gradagem (47.976 kcal ha ${ }^{-1}$ ) e destorroamento com rotativa de micro-trator $\left(10.035 \mathrm{kcal} \mathrm{ha}^{-1}\right)$ - Ferraro Júnior, 1999.

Serviços manuais: Os gastos calóricos das diversas atividades executadas foram obtidos por estimativa, proporcionalmente ao esforço necessário na realização de cada atividade, balizados no valor médio de $2.400 \mathrm{kcal} \mathrm{dia}^{-1}$ (300 kcal hora ${ }^{-1}$ - Gliessman (2000) e Ferraro Júnior (1999).

- $1.000 \mathrm{kcal} \mathrm{dia}^{-1}$ : Irrigações, classificação, embalagem, colheita com esforço leve (colher sementes botânicas e similares).

- $1.500 \mathrm{kcal} \mathrm{dia}^{-1}$ : Preparo de sementeira, aplicação de calcário, plantio, desbaste.

- $2.400 \mathrm{kcal} \mathrm{dia}^{-1}$ : preparo de mudas, capinas a mão, amarrio, desbrota, capação, pulverizações, lavagem e manuseio de produtos, transporte interno, colheita com esforço médio (abóbora, alho, cenoura, couve-flor, repolho e tomate).

- $3.200 \mathrm{kcal} \mathrm{dia}^{-1}$ : obtenção e aplicação de cobertura morta.

- $3.600 \mathrm{kcal} \mathrm{dia}^{-1}$ : distribuição de composto, adubação orgânica em cobertura, aplicação de biofertilizante líquido, estaqueamento.

- $4.000 \mathrm{kcal} \mathrm{dia}^{-1}$ : preparo manual do solo (sulcamento, coveamento), amontoa, capinas com enxada, colheita com esforço pesado (batata, taro, batata-baroa, batata-doce).

Irrigação: Os valores calóricos foram estimados para cada cultura, baseando-se nos dados médios do consumo de água na irrigação e nos valores médios de $0,131 \mathrm{kwh}$ por $\mathrm{m}^{3}$ de água e $860 \mathrm{kcal}$ por kwh - Lima et al. (2005).
Embalagens plásticas: Baseou-se no peso das embalagens e no valor energético de $9.000 \mathrm{kcal} \mathrm{kg}^{-1}$ dos plásticos (bandejas de poliestireno expandido e filmes de polietileno), segundo Sakurai (2004) e IPT (2005). Os custos de 1000 unidades para cada tipo de embalagem foram: bandeja e filme plástico para embalagem de $500 \mathrm{~g}$ (72.000 kcal 1000 $\left.\mathrm{ud}^{-1}\right)$; bandeja e filme plástico para embalagem de $1 \mathrm{~kg}\left(90.000 \mathrm{kcal} 1000 \mathrm{ud}^{-1}\right)$; filme plástico para embalagem de abóbora e repolho $(21.060 \mathrm{kcal}$ $\left.1000 \mathrm{ud}^{-1}\right)$.

Frete: $880 \mathrm{kcal}$ por $\mathrm{t} \mathrm{km}^{-1}$, obtido pela razão entre o custo energético total do setor, relatados no BEN 2005 (Ministério, 2005) e o volume de carga transportada (Agência, 2005).

Valor calórico dos produtos: Utilizaram-se os valores médios descritos por Franco (1999), tendo por base o peso fresco das hortaliças.

O balanço energético foi obtido, relacionando-se as quantidades de energia embutidas nos produtos comerciais (produtividade após a seleção e classificação), pelo total de energia investida na produção (embutida nos insumos, serviços, equipamentos e frete), obtendo-se assim a quantidade de energia obtida para cada unidade de energia investida $\left(\mathrm{kcal} \mathrm{kcal}^{-1}\right)$.

\section{Resultados e Discussão}

Os coeficientes técnicos da Tabela 1, transformados em seus respectivos valores calóricos estão apresentados na Tabela 2. A cultura da abóbora orgânica foi a que apresentou menores gastos com embalagens plásticas e também menores gastos totais de energia. As culturas do alho e repolho apresentaram gastos intermediários com embalagens, devido ao alho ser naturalmente uma espécie de pequena produção de biomassa comercial por hectare em relação às outras hortaliças e devido ao repolho ser uma espécie que, mesmo apresentando alta produção de biomassa, emprega apenas o filme plástico para envolver as cabeças. Para as demais culturas analisadas verificou-se alto dispêndio energético com o uso de embalagens plásticas para a venda dos produtos orgânicos no mercado, chegando a atingir gastos próximos a 5 milhões de kcal ha ${ }^{-1}$.

Em média, o sistema orgânico gastou 1.906.302 $\mathrm{kcal} \mathrm{ha}^{-1}$ com embalagens, de um total 


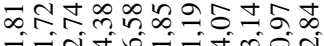

可

茜

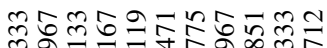

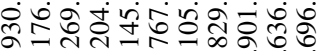
तो

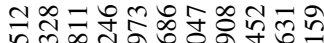

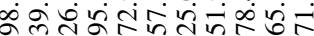

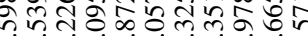

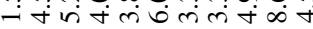

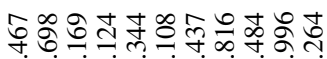

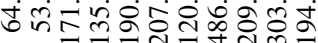

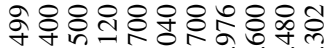
nion - तं ल- -

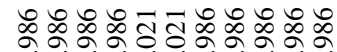
$\infty \infty \infty \infty \dot{0} \infty \infty_{\infty} \infty \infty$

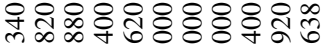

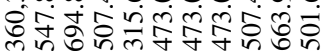

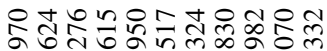
ปૈ

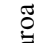

de 4.571.159 $\mathrm{kcal} \mathrm{ha}^{-1}$. Percebe-se que este valor elevado para embalar os produtos limitou o balanço energético médio a $2,84 \mathrm{kcal} \mathrm{kcal}^{-1}$. A diminuição dos gastos com embalagens favoreceria a eficiência energética do sistema.

A Tabela 3 apresenta a distribuição percentual da participação de todos os componentes no gasto energético total para cada cultura no sistema orgânico. Verifica-se que as embalagens tem sido responsáveis por grande parte dos investimentos energéticos nos cultivos orgânicos das hortaliças - em muitos casos, o principal componente. Em média, representaram $35,8 \%$ do total da entrada de energia na produção orgânica das culturas. Pelo fato de não empregar bandejas de isopor, mas apenas o filme plástico, as embalagens de abóbora foram aquelas que menos oneraram energeticamente o sistema de produção orgânica, participando com $4,6 \%$ dos custos energéticos totais. Contrariamente, as embalagens de tomate foram aquelas que mais oneraram, representando 57,4\% dos custos.

Em geral, verificou-se a existência de relação direta entre a porcentagem de participação das embalagens nos custos, com a quantidade de biomassa comercial produzida pela mesma e o peso padrão usado para compor cada embalagem $(0,5 \mathrm{~kg}, 1,0 \mathrm{~kg}$ ou unidade de produto). Dois exemplos explicam esses fatos: 1) na comercialização de alho e cenoura orgânicos utilizam-se o mesmo padrão de embalagem $(0,5 \mathrm{~kg}$ por bandeja), mas estas representaram 19,4\% do custo energético no alho, que produziu $6.102 \mathrm{~kg}$ de biomassa comercial por ha, contra 55,9\% na cenoura, que produziu $23.535 \mathrm{~kg}$ $\mathrm{ha}^{-1}$. 2) o taro e a cenoura produziram rendimentos comerciais similares $\left(23.805\right.$ e $23.535 \mathrm{~kg} \mathrm{ha}^{-1}$, respectivamente), mas por utilizarem padrões de embalagens diferentes $(1,0 \mathrm{~kg}$ para o taro e $0,5 \mathrm{~kg}$ para a cenoura), as participações destas nos custos energéticos totais também foram diferenciados, inversamente proporcional à capacidade da embalagem, com $34,4 \%$ para o taro, contra $55,9 \%$ para a cenoura (Tabela 3 ).

A eliminação apenas das embalagens das hortaliças poderia reduzir expressivamente os custos energéticos no sistema orgânico, com reflexos positivos na eficiência e no balanço energético de todas as culturas analisadas. Em média, esta ausência de gastos de 35,8\% com embalagens, elevaria a eficiência energética, aumentando o balanço médio de 2,84 até 5,18 $\mathrm{kcal} \mathrm{kcal}^{-1}$ (Tabela 4). O aumento no balanço energético para as espécies com menores 
Tabela 3: Participação porcentual dos componentes nos custos energéticos totais de 10 culturas olerícolas em sistema orgánico. INCAPER: Domingos Martins, ES, $2006^{1}$

\begin{tabular}{|c|c|c|c|c|c|c|c|c|}
\hline \multirow[b]{2}{*}{ Culturas } & \multicolumn{8}{|c|}{ Componentes (\%) } \\
\hline & $\begin{array}{l}\text { Sementes } \\
\text { ou mudas }\end{array}$ & Composto & $\begin{array}{l}\text { Caldas e } \\
\text { Insumes }\end{array}$ & $\begin{array}{c}\text { Servico } \\
\text { Mecánico }\end{array}$ & $\begin{array}{l}\text { Máo } \\
\text { Obra }\end{array}$ & Irrigacáo & $\begin{array}{l}\text { Emba- } \\
\text { lagem }\end{array}$ & Frete \\
\hline Abóbora & 25,5 & 24,1 & 0 & 11,5 & 7,7 & 22,5 & 4,6 & 4,0 \\
\hline Alho & 25,3 & 17,0 & 2,7 & 4,0 & 18,3 & 12,1 & 19,4 & 1,2 \\
\hline Batata & 18,5 & 14,8 & 2,9 & 3,5 & 10,3 & 13,3 & 33,5 & 3,3 \\
\hline Batata-baroa & 0,9 & 12,6 & 0 & 4,5 & 12,4 & 12,4 & 54,0 & 3,3 \\
\hline Batata-doce & 1,4 & 19,9 & 0 & 5,0 & 10,4 & 8,1 & 50,3 & 4,9 \\
\hline Cenoura & 8,0 & 12,7 & 0 & 3,2 & 8,9 & 7,8 & 55,9 & 3,4 \\
\hline Couve-flor & 1,8 & 23,2 & 0 & 5,5 & 8,2 & 14,2 & 43,4 & 3,6 \\
\hline Repolho & 12,2 & 23,0 & 0 & 5,5 & 10,3 & 14,1 & 20,4 & 14,5 \\
\hline Taro & 27,9 & 10,3 & 0 & 3,7 & 9,3 & 10,2 & 34,4 & 4,2 \\
\hline Tomate & 0,1 & 8,9 & 8,6 & 2,1 & 11,7 & 7,7 & 57,4 & 3,5 \\
\hline Media & 12,4 & 17,2 & 1,5 & 5,0 & 11,0 & 12,6 & 35,8 & 4,5 \\
\hline Desv. padráo & 11,4 & 5,6 & - & 2,5 & 3,1 & 4,3 & 17,2 & 3,6 \\
\hline C.V. $(\%)$ & 91,9 & 32,4 & - & 50,8 & 27,7 & 34,2 & 48,1 & 80,5 \\
\hline
\end{tabular}

${ }^{1}$ Os valores, para cada especie, sao medias de varios cultivos no período de 1991 a 2000.

Tabela 4: Balado e participação das embalagens plásticas nos custos energéticos de hortaliças orgânicas. INCAPER: Domingos Martins, ES, 2006.

\begin{tabular}{|c|c|c|c|}
\hline \multirow{2}{*}{ Culturas (embalagens) } & \multicolumn{2}{|c|}{ Batanço energético } & \multirow{2}{*}{$\begin{array}{c}\text { Participação relativa das } \\
\text { embalagens } \\
(\%)\end{array}$} \\
\hline & $\begin{array}{c}\text { Balanço COM embalagem } \\
\left(\mathrm{kcal} \mathrm{kcal}^{-1}\right)\end{array}$ & $\begin{array}{c}\text { Balanco SEM embalagens } \\
\left(\mathrm{kcal} \mathrm{kcal}^{-1}\right)\end{array}$ & \\
\hline Abóbora (filmes plásticos p/ 1 ud) & 1,81 & 1,92 & 4,6 \\
\hline Alho (bandejas de $500 \mathrm{~g}$ ) & 1,72 & 2,23 & 19,4 \\
\hline Batata (bandejas de $1 \mathrm{~kg}$ ) & 2,74 & 4,39 & 33,5 \\
\hline Batata-baroa (bandejas de $500 \mathrm{~g}$ ) & 4,38 & 10,19 & 54,0 \\
\hline Batata-doce (bandejas de $1 \mathrm{~kg}$ ) & 6,58 & 14,09 & 50,3 \\
\hline Cenoura (bandejas de $500 \mathrm{~g}$ ) & 1,85 & 4,41 & 55,9 \\
\hline Couve-flor (bandejas p/ 1 ud) & 1,19 & 2,18 & 43,4 \\
\hline Repolho (bandejas p/ 1 ud) & 4,07 & 5,18 & 20,4 \\
\hline Taro (bandejas $1 \mathrm{~kg}$ ) & 3,14 & 4,87 & 34,4 \\
\hline Tomate (bandejas de $500 \mathrm{~g}$ ) & 0,97 & 2,34 & 57,4 \\
\hline Media & 2,84 & 5,18 & 35,8 \\
\hline
\end{tabular}

gastos com embalagens, como abóbora e alho, seriam consequentemente menos intensos. Porém, para espécies em que os gastos com embalagens são maiores, como batata-baroa, batata-doce, cenoura e tomate, este aumento seria muito significativo, atingindo até $140 \%$.
Diante dos altos custos energéticos das embalagens, deve-se atentar que maiores produtividades na produção orgânica de hortaliças, apesar de representarem melhor balanço de energia, significam também maior custo relativo com embalagens, uma vez que os gastos com embalagens aumentariam em 

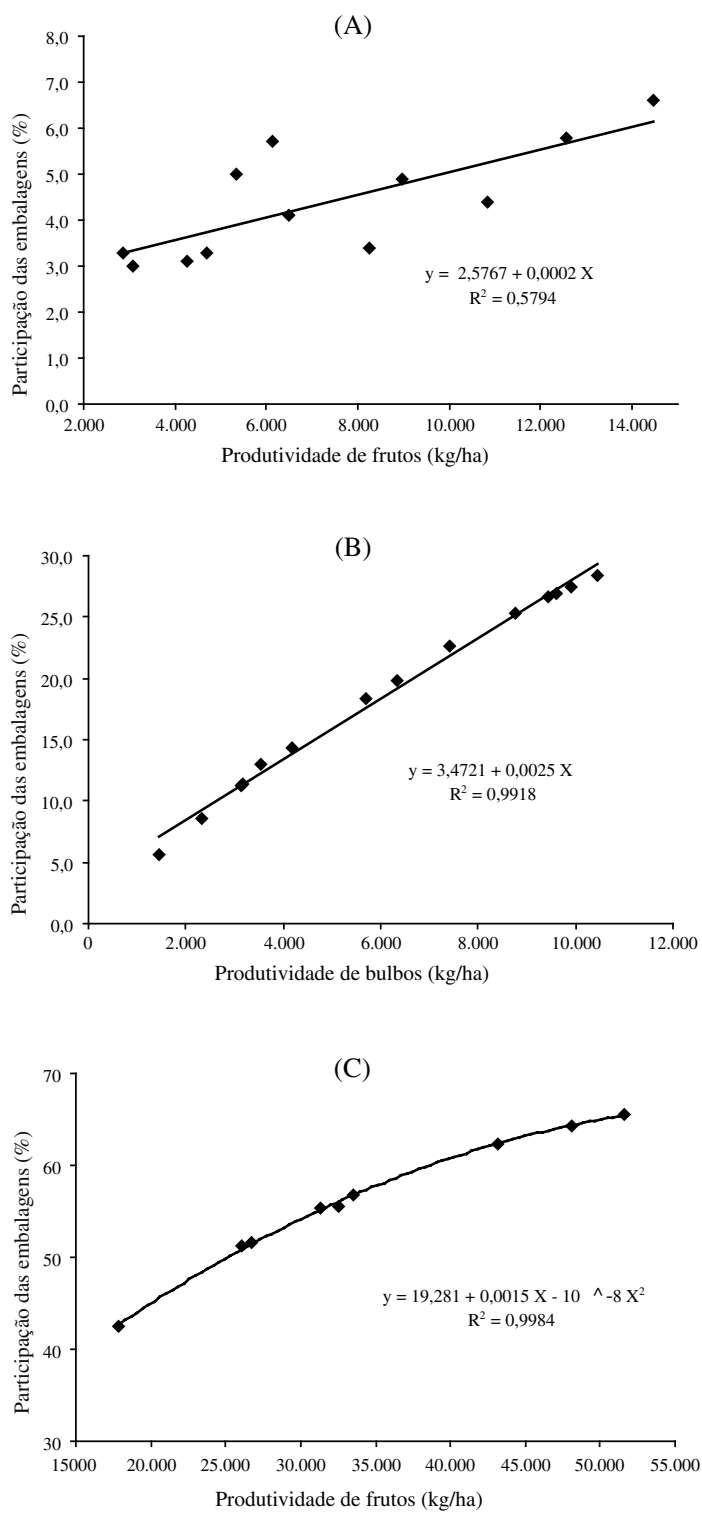

Figura 1: Relação entre a produtividade de abóbora (A), alho (B) e tomate (C), com a participação das embalagens nos custos energéticos totais de cada cultura. INCAPER: Domingos Martins, ES, 2006. maior proporção do que os gastos com outros componentes. Isto pode ser verificado nas ilustrações da Figura 1, para as culturas de abóbora, alho e tomate. A dispersão das produtividades dos diversos campos das culturas analisadas, relacionadas às respectivas participações das embalagens, comprova uma relação direta entre estes dois componentes.

Os elevados custos energéticos das embalagens induzem a três reflexões importantes - a primeira é que a cadeia de alimentos orgânicos demonstra que a produção tem caráter agroecológico e orgânico, mas o mercado mantém toda estrutura convencional, não priorizando redução de custos energéticos; a segunda reforça a importância de priorizar vias de comercialização de maior aproximação do produtor com o consumidor, através de feiras livres e entregas por cestas, sem emprego de embalagens plásticas; a terceira confirma a necessidade de desenvolvimento de alternativas de embalagens ecológicas, para redução da poluição ambiental e minimização de custos energéticos na produção orgânica.

\section{Conclusões}

A utilização de embalagens plásticas para hortaliças orgânicas representa alto custo energético do sistema de produção.

A utilização de embalagens plásticas para batata, batata-baroa, batata-doce, cenoura, couve-flor, taro e tomate orgânicos representa o principal custo energético do sistema de produção destas culturas.

A utilização de embalagens plásticas para alho e repolho orgânicos representa o segundo componente de maior custo energético do sistema de produção destas culturas.

A utilização de embalagens plásticas para abóbora orgânica representa baixo custo energético do sistema de produção desta cultura.

A opção por sistemas de comercialização e venda de hortaliças orgânicas que dispensem o emprego de embalagens plásticas, pode aumentar a eficiência energética, elevando o balanço energético médio de 2,84 para 5,18 $\mathrm{kcal} \mathrm{kcal}^{-1}$.

\section{Literatura Citada}

Agência Nacional De Transportes Terrestres 2005 Transportes terrestres, números do setor. Brasília-DF. Capturado em 08 dez. 2005. Online. Disponível na Internet http://www.antt.gov.br.

Ferraro Júnior, L.

1999 A. Proposição de método de avaliação de sistemas de produção e de sustentabilidade. São Paulo. Tese (Mestrado). Escola Superior de Agricultura "Luiz de Queiroz/USP. 131 p.
Franco, G.

1999 Tabela de composição química dos alimentos. 9 ed. São Paulo: Editora Atheneu, 307 p.

Gliessman, S.

2000 Agroecologia: processos ecológicos em agricultura sustentável. Ed. Universidade/UFRGS. Porto Alegre, $653 \mathrm{p}$. 
IPT

2005 Linhas e Projetos de Pesquisa: Plástico Biodegradável. Capturado em 10 nov. 2005. Online. Disponível na Internet http://www.ipt.br

Li, F.; Gao, C.; Zhao, H.; Li, X.

2002 Soil conservation effectiveness and energy efficiency of alternative rotations and continuous wheat cropping in the Loess Plateau of northwest China. Agric., Ecos. \& Env., 91: 101-111.

Lima, J. E. F. W. et al.

2005 O uso da irrigação no Brasil. Capturado em 16 nov. 2005. Online. Disponível na Internet http://www.cf.org.br/ cf2004/irrigacao.doc

Mansvelt, J. D.; Stobbelaar, D. J.; Hendriks, K.

1998 Comparison of landscape features in organic and conventional farming systems. Landscape and Urban Planning, 41: 209-227.

Mello, R.

1989 Um modelo para análise energética de agroecossistemas. São Paulo. Rev. Adm. Emp., 29 (4): 45-61.

Ministério Das Minas e Energia

2005 Boletim Energético Nacional - BEN. Brasília, p. 129.

Pimentel, D. (Ed.)

1980 Handbook of energy utilization in agriculture. Florida: CRC Press, $475 \mathrm{p}$.

Pimentel, D.; Dazhong, W.; Giampietro, M.

1990 Technological changes in energy use in U.S. agricultural production. In: Gliessman, S. R. (Ed). Agroecology: Researching the ecological basis for sustainable agriculture. Springer-Verlag, New York, p. 305-321. (Ecological Studies, 78).
Poudel, D. D.; Horwath, W. R.; Lanini, W. T.; Temple, S. R.; Bruggen, A. H. C.

2002 Comparison of soil $\mathrm{N}$ availability and leaching potential, crop yields and weeds in organic, low-input and conventional farming systems in northean California. Agr., Ecos. \& Env., 90: 125-137.

Reganold, J. P.; Glover, J. D.; Andrews, P. K.; Hinman, H. R. 2001 Sustainability of three apple production systems. Nature, 410: 926-929.

Sakurai, K.

2004 HDT 17: Método sencillo del análisis de residuos sólidos. Washington: Organización Panamericana de la Salud. Disponível em: <http://www.bvsde.ops-oms.org/ sde/ops-sde/bv-residuos.shtml>. Acesso em 20 jul. 2004.

Santos, H. P.; Fontaneli, R. S.; Ignaczak, J. C.; Zoldan, S. M.

2000 Conversão e balanço energético de sistemas de produção de grãos com pastagens sob plantio direto. Pesq. Agrop. Bras., Brasília, 35 (4): 743-752.

Souza, J. L. de

2005 Agricultura Orgânica: tecnologias para a produção de alimentos saudáveis. $2 \mathrm{~V}$. Vitória: INCAPER, $257 \mathrm{p}$.

Souza, J. L. de

2006 Balanço energético em cultivos orgânicos de hortaliças. Viçosa: UFV. 207 p. (Tese de Doutorado).

Souza, J. L. de; Resende, P.

2003 Manual de Horticultura Orgânica. Viçosa: Aprenda Fácil, 560 p. il.

Uri, N. D.; Atwood, J. D.; Sanabria, J.

1998 The environmental benefics and costs of conservation tillage. The Science of the Total Environment, 216: 13-32.

Waldon, H.; Gliessman, S. R.; Buchanan, M.

1998 Agroecosystem responses to organic and conventional management practices. Agric. Syst., 57 (1): 65-75. 